\title{
Phenological change detection while accounting for abrupt and gradual trends in satellite image time series
}

\author{
Jan Verbesselt ${ }^{\mathrm{a}, *}$, Rob Hyndman ${ }^{\mathrm{b}},{\text { Achim } \text { Zeileis }^{\mathrm{c}} \text {, Darius Culvenor }}^{\mathrm{a}}$ \\ ${ }^{a}$ Remote sensing team, CSIRO, Private Bag 10, Melbourne VIC 3169, Australia \\ ${ }^{b}$ Department of Econometrics and Business Statistics, Monash University, Melbourne VIC 3800, Australia \\ ${ }^{c}$ Institute for Statistics, Leopold-Franzens-Universitt Innsbruck, 6020 Innsbruck, Austria
}

\begin{abstract}
A challenge in phenology studies is understanding what constitutes phenological change amidst background variation. The majority of phenological studies have focussed on extracting critical points in the seasonal growth cycle, without exploiting the full temporal detail. The high degree of phenological variability between years demonstrates the necessity of distinguishing long term phenological change from temporal variability. Here, we demonstrate the phenological change detection ability of a method for detecting change within time series. BFAST, Breaks For Additive Seasonal and Trend, integrates the decomposition of time series into trend, seasonal, and remainder components with methods for detecting change. We tested BFAST by simulating 16-day NDVI time series with varying amounts of seasonal amplitude and noise, containing abrupt disturbances (e.g. fires) and long term phenological changes. This revealed that the method is able to detect the timing of phenological changes within time series while accounting for abrupt disturbances and noise. Results showed that the phenological change detection is influenced by the signal-to-noise ratio of the time series. Between different land cover types the seasonal amplitude varies and determines the signal-to-noise ratio, and as such the capacity to differentiate phenological changes from noise. Application of the method on 16-day NDVI MODIS images from 2000 until 2009 for a forested study area in south eastern Australia confirmed these results. It was shown that a minimum seasonal amplitude of 0.1 NDVI is required to detect phenological change within cleaned MODIS NDVI time series using the quality flags. BFAST identifies phenological change independent of phenological metrics by exploiting the full time series. The method is globally applicable since it analyzes each pixel individually without the setting of thresholds to detect change within a time series. Long term phenological changes can be detected within NDVI time series of a large range of land cover types (e.g. grassland, woodlands and deciduous forests) having a seasonal amplitude larger than the noise level. The method can be applied to any time series data and it is not necessarily limited to NDVI.
\end{abstract}

Keywords: phenology, change detection, time series, disturbance, climate change, remote sensing, NDVI, MODIS

*Corresponding author. Ph: +61395452265 ; Fax: +61395452448

Email address: Janverbesselt@gmail.com (Jan Verbesselt) 


\section{Introduction}

Natural resource managers, policy makers and researchers demand knowledge of phenological dynamics over increasingly large spatial and temporal extents for addressing pressing issues related to global environmental change such as biodiversity, primary production and

5 carbon emissions (Cleland et al., 2007; White and Nemani, 2003). Changes in the timing and length of the growing season may not only have consequences for plant and animal ecosystems, but persistent increase in length may lead to long-term increase in carbon storage and changes in vegetation cover (Linderholm, 2006). Causal attribution of recent biological trends to climate change however is complicated because non-climatic influences, such as land use change, dominate local, short-term biological changes (Parmesan and Yohe, 2003).

Long-term observations of plant phenology have been used to track vegetation responses to climate variability but are often limited to particular species and locations (Schwartz, 1999). Satellite data possess significant potential for monitoring vegetation dynamics at regional to global scales because of the synoptic coverage and regular temporal sampling (Anyamba and Eastman, 1996; Azzali and Menenti, 2000). Land surface phenology (LSP), is the study of spatio-temporal development of the vegetated land surface in relation to climate as revealed by satellite sensors (de Beurs and Henebry, 2005a). LSP is indirectly related to plant phenology via the absorption and reflectance of radiation but is influenced by atmospheric scatter, cloud and snow cover, bidirectional reflectance effects and nonclimatic factors influencing the land surface (e.g. biogenic or anthropogenic disturbances) (White et al., 2009).

Although the value of remotely sensed long term data sets for change detection has been firmly established, only a limited number of time series change detection methods have been developed. Estimating change from remotely sensed data is not straightforward, since time series contain a combination of phenological and trend changes, in addition to noise that originates from remnant geometric errors, atmospheric scatter and cloud effects (de Beurs and Henebry, 2005b; Verbesselt et al., 2010). Three major challenges stand out.

First, the majority of remote sensing phenology studies have focussed on extracting phenological metrics from time series of normalized difference vegetation index (NDVI) (Reed et al., 2003; White et al., 2009; Zhang et al., 2003). The concept of deriving phenological metrics is based on identifying critical points in the seasonal NDVI trajectory 
that corresponds to, for example, the start-of-spring (SOS). Phenological metrics exploit the information contained in the shape of the seasonal growth cycle, but do not fully utilize its full temporal detail (Geerken, 2009). Based on a intercomparison of ten SOS estimation methods for North America between 1982 and 2006, White et al. (2009) demonstrated that SOS estimates vary extensively within and among methods. Moreover, the high degree of phenological variability (e.g. in SOS) between years demonstrates the necessity of distinguishing temporal variability from phenological change (Bradley et al., 2007). Consequently, there is a need for a more robust approach to detect long term phenological changes based on full time series, not just dates of specific events (White and Nemani, 2006).

Second, methods must allow for the detection of changes within complete long term data sets. Several approaches have been proposed for analyzing image time series, such as principal component analysis (PCA) (Crist and Cicone, 1984), wavelet decomposition (Anyamba and Eastman, 1996), Fourier analysis (Bradley et al., 2007; Eastman et al., 2009) and change vector analysis (CVA) (Lambin and Strahler, 1994). These time series analysis approaches discriminate noise from the signal by its temporal characteristics but involve some type of transformation designed to isolate dominant components of the variation across years of imagery through the multi-temporal spectral space. The challenge of these methods is the labeling of the change components, because each analysis depends entirely on the specific image series analyzed. Furthermore, change in time series is often masked by seasonality driven by yearly temperature and rainfall variation. Existing change detection techniques minimize seasonal variation by focussing on specific periods within a year (e.g. growing season) (Coppin et al., 2004) or temporally summarizing time series data (Bontemps et al., 2008; Fensholt et al., 2009) instead of explicitly accounting for changes in seasonality.

Third, recent studies of LSP have highlighted that a broader consideration of nonclimatic factors (e.g. fires, land degradation or land management) influencing phenology is critical (Julien and Sobrino, 2009; White et al., 2009). Even in unpopulated regions of the world with low levels of human activity, biogenic and anthropogenic disturbances such as insect attacks, fires, floods, or deforestation would significantly influence LSP (Potter et al., 2003). A challenge to phenology studies is understanding what constitutes significant change in LSP amidst background variation (e.g. fires, land degradation, and 
noise) (de Beurs and Henebry, 2005a). The ability of any system to detect change depends on its capacity to account for variability at one scale (e.g. seasonal variations), while identifying change at another (e.g. multi-year trends). As such, change in terrestrial plant ecosystems can be divided into three classes (de Beurs and Henebry, 2005a; Verbesselt et al., 2010): (1) phenological change, a significant change in the seasonal shape. Between years, phenological markers (e.g. SOS) are affected by short-term climate fluctuations (e.g. temperature and rainfall). Over a longer time period, annual phenologies might shift, i.e. phenological change, as a result of climate changes or large scale anthropological disturbances (Potter et al., 2003) (2) abrupt change, a step change caused by disturbances such as deforestation, floods, and fires or sensor errors (Holben, 1986); and (3) gradual change, a linear trend triggered by a gentle change in seasonality, land degradation or long term trends in mean annual rainfall.

Here, we demonstrate the ability of BFAST, Breaks For Additive Seasonal and Trend, to detect long term phenological change in satellite image time series. The method integrates the iterative decomposition of time series into trend, seasonal and remainder components with methods for detecting changes within time series. Verbesselt et al. (2010) successfully demonstrated the ability of BFAST to detect changes within the trend component of satellite image time series. However, while the original BFAST approach includes a seasonal component that can in principle capture phenological changes, this capacity was not yet fully exploited and validated. The present study fills this gap by demonstrating BFAST's capacity to detect long term phenological changes within time series. We implement a harmonic seasonal model which requires fewer observations, is more robust against noise, and of which the parameters can be more easily used to characterize phenological change. We assess BFAST's ability to estimate phenological changes within time series for a large range of ecosystems by simulating NDVI time series and applying the approach on MODIS 16-day NDVI image composites from 2000 until 2009. The methods are available in the BFAST package for R (R Development Core Team, 2009) from CRAN (http://cran.r-project.org/package=bfast).

\section{Detecting phenological change within time series}

Here, we explain the key concepts and characteristics of the BFAST algorithm while focussing on it's capacity to detect phenological changes within time series. While the 
original BFAST approach includes a seasonal dummy model, the present manuscript demonstrates BFAST's capacity to detect long term phenological changes by using a harmonic seasonal model.

\subsection{Decomposition model}

An additive decomposition model is used to iteratively fit a piecewise linear trend and a seasonal model. The general model is of the form

$$
Y_{t}=T_{t}+S_{t}+e_{t} \quad(t=1, \ldots, n)
$$

Verbesselt et al. (2010) implemented a piecewise linear seasonal model using seasonal dummy variables (Makridakis et al., 1998, pp. 269-274) to fit the seasonal component. Here, we employ a different parametrization of the seasonal component that proves to be more suitable and robust for phenological change detection with satellite image time series. Let the seasonal breakpoints be given by $\tau_{1}^{\#}, \ldots, \tau_{p}^{\#}$, and again define $\tau_{0}^{\#}=0$ and $\tau_{p+1}^{\#}=n$. Then suppose $S_{t}$ is a harmonic model for $\tau_{j-1}^{\#}<t \leq \tau_{j}^{\#}(j=1, \ldots, p)$ and $K$ the number of harmonic terms:

$$
S_{t}=\sum_{k=1}^{K} a_{j, k} \sin \left(\frac{2 \pi k t}{f}+\delta_{j, k}\right)
$$

where the unknown parameters are the segment-specific amplitude $a_{j, k}$ and phase $\delta_{j, k}$ and $f$ is the (known) frequency (e.g. $f=23$ annual observations for a 16-day time series). While 
Eq. (3) emphasizes the harmonic interpretation, Eq. (4) is a convenient transformation to a multiple linear harmonic regression model with coefficients $\gamma_{j, k}=a_{j, k} \cos \left(\delta_{j, k}\right)$ and $\theta_{j, k}=a_{j, k} \sin \left(\delta_{j, k}\right)$ that can be easily estimated:

$$
S_{t}=\sum_{k=1}^{K}\left[\gamma_{j, k} \sin \left(\frac{2 \pi k t}{f}\right)+\theta_{j, k} \cos \left(\frac{2 \pi k t}{f}\right)\right]
$$

The amplitude and phase at frequency $f / k$ are given by $a_{j, k}=\sqrt{\gamma_{j, k}^{2}+\theta_{j, k}^{2}}$ and $\delta_{j, k}=$ $\tan ^{-1}\left(\theta_{j, k} / \gamma_{j, k}\right)$ respectively. In summary, the harmonic model (Eq. 3) offers three main advantages when compared to the seasonal dummy model: (1) the model is less sensitive to short term data variations and inherent noise (e.g. clouds and atmospheric scatter) when selecting lower frequency harmonic terms, (2) fewer observations are required since fewer parameters need to be estimated in the multiple regression model which increases speed and efficiency of the algorithm, and (3) the fitted parameters (i.e. $a_{j}$ and $\delta_{j}$ ) can more easily be used to characterize phenological change. We used three harmonic terms (i.e. $K=3$ ) to robustly detect phenological changes within MODIS NDVI time series, as components four and higher represent variations that that occur on a three-month cycle or less (Geerken, 2009; Julien and Sobrino, 2010). Although the main phenological change detection concept remains the same for the two seasonal models, the harmonic model offers advantages when processing satellite image time series. Inter-annual variations in plant phenology (i.e. growth cycle) have been studied by the estimated amplitude and phase using harmonic analysis (Geerken, 2009; Wagenseil and Samimi, 2006; Eastman et al., 2009). Harmonic analysis has mainly been used to characterize the seasonal growth cycle of a single year for land cover classification purposes (Geerken, 2009; Wagenseil and Samimi, 2006) whereas trends in the parameters of the fitted harmonics (e.g. amplitudes and phases) were studied by Eastman et al. (2009). Here, we implement the harmonic seasonal model within an iterative change detection procedure to distinguish between significant phenological changes from background variations (e.g. noise and small annual phenological variations).

\subsection{Iterative detection of change within time series}

Although being rather intuitive, the segmented decomposition model (Eq. 1) is not straightforward to estimate. The trend breakpoints $\tau_{i}^{*}(i=1, \ldots, m)$ and corresponding 
segment-specific intercept $\alpha_{i}$ and $\beta_{i}$ have to be determined, along with the seasonal breakpoints $\tau_{j}^{\#}(j=1, \ldots, p)$ and corresponding segment-specific amplitude $a_{k, j}$ and phase $\delta_{k, j}$ for frequencies $23 / k(k=1,2,3)$. Furthermore, the model selection has to determine the number of required segments in the trend $(m+1)$ and seasonal $(p+1)$ component, respectively. However, once the breakpoints are known, estimation of trend and season parameters is straightforward. The optimal position of these breaks can be determined by minimizing the residual sum of squares, and the optimal number of breaks can be determined by minimizing an information criterion. Bai and Perron (2003) argue that the Akaike Information Criterion usually overestimates the number of breaks, but that the Bayesian Information Criterion (BIC) is a suitable selection procedure in many situations (Zeileis et al., 2002, 2003; Zeileis and Kleiber, 2005).

Before fitting the piecewise linear models and estimating the breakpoints it is recommended to test whether breakpoints are occurring in the time series . The ordinary least squares residuals-based moving sum (MOSUM) test, is selected to test for whether one or more breakpoints occur (Zeileis, 2005). If the test indicates significant change $(p<0.05)$, the breakpoints are estimated using the method of Bai and Perron (2003), as implemented by Zeileis et al. (2002), where the number of breaks is determined by the BIC, and the date and confidence interval of the date for each break are estimated. The confidence interval of the break date indicates a 95\% confidence interval of date estimation (also indicates the reliability of the date estimation).

We have followed recommendations of Bai and Perron (2003) concerning the fraction of data needed between breaks. We used a minimum of two years of data (i.e. 46 observations in 16-day time series) between successive change detections within a 10-year time series (2000-2009). By selecting a minimum two years of data required between potentially detected phenological changes, longer term phenological changes (2-years and more) are detected while being robust against high variability between successive years (i.e. atypical years). In case BFAST is applied on longer satellite image time series (e.g. AVHRR NDVI time series from 1980-2006), we would recommend using multiple years (e.g. 5) for the detection of long term phenological change. We hereby want to caution that the definition of long term phenological change is relative and that in this study it indicates multiple years (more than 2) whereas a satellite image time series of 10 or 25 years are still relatively short for detecting long term phenological changes (White et al., 2009). 
The iteration is initialized with an estimate of $\hat{S}_{t}$ from a standard season-trend de-

composition. The estimation of parameters is then performed by iterating through the following steps until the number and position of breakpoints are unchanged:

Step 1 If the OLS-MOSUM test indicates that breakpoints are occurring in the trend component, the number and position of the trend breakpoints $\left(\tau_{1}^{*}, \ldots, \tau_{m}^{*}\right)$ are estimated via least squares from the seasonally adjusted data $Y_{t}-\hat{S}_{t}$.

Step 2 The trend coefficients $\alpha_{i}$ and $\beta_{i}$ are estimated (given the trend breakpoints) using robust regression based on M-estimation to account for potential outliers (Venables and Ripley, 2002, pp.156-163). This yields the trend estimate $\hat{T}_{t}=\hat{\alpha}_{i}+\hat{\beta}_{i} t$ based on Eq. (2).

Step 3 If the OLS-MOSUM test indicates that breakpoints are occurring in the seasonal component, the number and position of the seasonal breakpoints $\left(\tau_{1}^{\#}, \ldots, \tau_{p}^{\#}\right)$ are estimated via least squares from the detrended data $Y_{t}-\hat{T}_{t}$.

Step 4 The seasonal coefficients $\gamma_{j, k}$ and $\theta_{j, k}$ are estimated (given the seasonal breakpoints) using robust regression based on M-estimation. This yields the seasonal component $\hat{S}_{t}=\sum_{k=1}^{3} a_{j, k} \sin \left(\frac{2 \pi k t}{f}+\delta_{j, k}\right)$ based on Eq. (3).

\section{Validation}

We validated the phenological change detection capacity of BFAST by (1) simulating 16-day NDVI time series containing phenological changes, and (2) applying the method to real 16-day MODIS satellite NDVI time series (2000-2009). Validation of multi-temporal change-detection methods is often not straightforward, since independent reference sources for a broad range of potential changes must be available during the change interval.

We simulated 16-day NDVI time series with different noise levels, seasonal amplitude, and disturbances in order to robustly test BFAST. However, it is challenging to simulate time series that approximate observed remotely sensed time series incorporating information on vegetation phenology, interannual climate variability, disturbance events, and signal contamination (e.g. clouds). Therefore, applying the method to remotely sensed data remains necessary. In the next two sections, we apply BFAST to 16-day simulated and real MODIS NDVI time series to assess its accuracy to estimate the number, timing of the detected seasonal changes. 


\subsection{Detecting phenological change in simulated NDVI time series} method for long time series.

$$
f(t) \equiv f\left(t ; a, b, c_{1}, c_{2}\right)=a \times\left\{\begin{array}{ll}
\exp \left[-(t-b)^{2} / c_{1}\right], & \text { if } t>b \\
\exp \left[-(b-t)^{2} / c_{2}\right], & \text { if } t<b
\end{array} .\right.
$$

The parameters $a, b$ determine the amplitude and the position of the maximum or minimum with respect to the independent time variable $t$, while $c_{1}$ and $c_{2}$ determine the width of the left and right hand side, respectively. Second, the noise component was generated using a random number generator that follows a normal distribution $\mathrm{N}(\mu=0, \sigma=x)$. Vegetation index specific noise was generated by randomly replacing the white noise by noise with a value of -0.1 , representing cloud contamination that often remains after atmospheric correction and cloud masking procedures. Third, an abrupt change was added to the trend component to simulate an abrupt disturbance (e.g. fire or insect attack). This was simulated by combining a step function with a -0.25 NDVI magnitude and fixed gradient recovery phase.

The accuracy of the method for estimating the number and timing of significant phenological changes within time series was assessed by adding phenological changes to the simulated time series. A phenological change is introduced by increasing the $c_{1}$ value between seasons, where $\Delta c_{1}$ is the difference in $c_{1}$ values between the next and previous season. Figure 1 illustrates a phenological change introduced from 2004 onwards by changing the $c_{1}$ value from 5 to 25 (i.e. $\Delta c_{1}=20$ ) while having $c_{2}=5, b=12$, and a seasonal amplitude $a$ of 0.3 NDVI (Eq. 5). We choose to simulate this type of phenological change corresponding to a shift in SOS because it is a central feature of global change research (White et al., 2009). However, the method identifies phenological change independent of its type (e.g. change in start, end, or length of the season, etc.) by exploiting the full time series and can be used as a generic phenological change detection 
To validate BFAST we simulated 16-day NDVI time series with two phenological changes in the seasonal component and one abrupt disturbance in the trend component (Fig. 2).

Table 1: Parameter values ( $a, \sigma$ noise and $\Delta c_{1}$ ) for simulation of 16-day NDVI time series while having $c_{1}=5, c_{2}=5$ and $b=12(E q .5)$ and where the $\Delta c_{1}$ values correspond to a shift in $S O S(\triangle S O S)$ expressed in days.

\begin{tabular}{ll}
\hline Parameters & Values \\
\hline$a$ & $0.1,0.3,0.5$ \\
$\sigma$ noise & $0.01,0.02, \ldots, 0.07$ \\
$\Delta c_{1}$ & $0,10,20,30$ \\
$\Delta S O S$ & $0,30,51,69$ \\
\hline
\end{tabular}

\subsection{Detecting phenological change in real MODIS image time series}

We selected the 16-day MODIS NDVI composites with a $250 \mathrm{~m}$ spatial resolution (MOD13Q1 collection 5), since this product provides frequent information at the spatial scale at which the majority of human-driven land cover changes occur (Townshend and Justice, 1988). The MOD13Q1 16-day composites were generated using a constrained view angle maximum NDVI value compositing technique (Huete et al., 2002). The MOD13Q1 images were acquired from 24 February 2000 to 14 September 2009 for a multi-purpose forested study area (Pinus radiata plantation) in South Eastern Australia (Lat. $35.5^{\circ} \mathrm{S}$, Lon. $148.0^{\circ} \mathrm{E}$ ). The abrupt and gradual changes occurring within the trend component of the MODIS satellite image time series for this study area are described by Verbesselt et al. (2010). Furthermore, the study area consists out of two very different land cover types, 
i.e. grasslands and plantations, providing time series with a large difference in seasonal amplitudes (i.e. 0.05-0.7 NDVI), ideal for assessing phenological change detection methods.

The images contain data from the red (620-670nm) and near-infrared (NIR, 841-876nm)

spectral bands. We used the binary MODIS Quality Assurance flags to select only cloud-free data of optimal quality. Moreover, a pixel time series was only selected for analysis when it lacked less than $10 \%$ of the data (de Beurs et al., 2009). This criterion was used to ensure the pixel time series contained sufficient data to estimate reliable trend and seasonal changes. Missing values were replaced by linear interpolation between neighboring values within the NDVI series (Verbesselt et al., 2006). The 16-day MODIS NDVI image series were analyzed, and the timing of the detected seasonal changes revealed were compared and interpreted with available land cover and climate data.

\section{Results}

\subsection{Detecting phenological change in simulated NDVI time series}

Figure 2 illustrates how BFAST decomposes and fits trend and seasonal time series components (red). It can be seen that the simulated (black) and estimated (red) components correspond well, and that the time of simulated (black) and detected (red) changes in the seasonal and trend component are similar (i.e. red and black dotted vertical lines). The sum of the estimated seasonal, trend and remainder series (red) equals the simulated data series (top panel of Fig. 2).

The accuracy (RMSE) of the number of estimated phenological changes caused by a simulated phenological change in $\Delta c_{1}$ at one point in time while varying $a$ and noise level are summarized in Figure 3. The noise level is expressed as $4 \sigma$, i.e. $99 \%$ of the noise range, to enable a comparison with the amplitude of the seasonal component. Two characteristics of the method are illustrated.

First, the signal-to-noise ratio (i.e. seasonal amplitude and the simulated phenological change versus noise level) has an influence on the RMSE for detecting the number of phenological changes. A larger a (i.e. seasonal amplitude of the time series), a larger $\Delta c_{1}$, or lower noise level results in more accurate detection of the number of phenological changes. For example, it is shown that when $a=0.1$, no phenological changes caused by $\Delta c_{1}$ are detected when the noise level is $>0.1$. Moreover, a phenological change caused by a $\Delta c_{1}=10$, which corresponds to a shift in SOS of 30 days (Table 1 ) within a 16-day 
time series, will only be detectable (i.e. RMSE $<2$ ) when $a>0.3$ and the noise level $<0.1$. This illustrates that BFAST is a signal-to-noise driven method which analyzes the full time series and detects abnormal or significant changes based on the signal versus noise distribution. Second, the noise level has minor influence on the phenological change detection when no changes are simulated (i.e. $\Delta c_{1}=0$ ), indicating a low commission error for detecting phenological changes (no false positives) (Fig. 3).

In Figure 4 RMSE's for estimating the timing of a phenological change within a time series caused by a change in $\Delta c_{1}$ are shown. Similarly, as in Figure 3 the RMSE results show that the time estimation by BFAST is influenced by the signal-to-noise ratio of the simulated time series. For example, when a phenological change is simulated by a difference in $\Delta c_{1}$ the estimation of time of change becomes more accurate (lower RMSE) for lower noise levels and higher $a$ (seasonal amplitude of the full time series). Overall, if the total length of the simulated 16-day time series is considered (i.e. 10 years) the RMSE for the detection of phenological change caused by a change in $\Delta c_{1}$ within a full time series remains low (i.e. $<3 \%$ of the length of the time series) for time series with a noise level $<0.15$ and a seasonal amplitude $a>0.1$.

\subsection{Detecting phenological change in real MODIS image time series}

Time of major phenological changes detected within 16-day NDVI image time series in a study area containing a $P$. radiata plantation surrounded by grasslands are shown in Figure 5. Almost no phenological changes are detected in the forest plantations whereas phenological changes are nearly always detected in the grasslands surrounding the forest plantation. These results confirm the simulation results by showing that the detection of phenological changes within time series is influenced by the signal-to-noise ratio of the time series. The overall seasonal amplitude of a NDVI time series is larger for a grassland than for an evergreen forest (i.e. plantation) whereas the noise levels within NDVI time series are similar.

Figures 6 and 7 are examples of detected phenological and trend changes within a NDVI time series (2000-2009) extracted from a single MODIS pixel within a grassland and a forest compartment located in the study area. Two phenological changes are detected in the seasonal component of a grassland NDVI time series (Fig. 6) whereas no phenological changes are detected in NDVI time series of a $P$. radiata plantation (Fig. 7). The figures illustrate the difference in signal-to-noise ratio for a grassland versus a forest NDVI time 
series. The most significant difference between a grassland and a forest NDVI time series is the data range of the seasonal component of 0.6 and 0.04 , respectively. Figure 7 illustrates that the detection of phenological changes in time series with a small signal-to-noise ratio (e.g.seasonal amplitude $<0.1$ NDVI versus a noise level of approximately $>0.1 \mathrm{NDVI}$ ) is not possible. These results confirm the simulation results by showing that the detection of phenological changes within time series is influenced by the signal-to-noise ratio of the time series.

Figure 5 illustrates that the major phenological changes detected in the grasslands occur in between 2005 and 2006. While the study area was experiencing below average annual rainfall since 2001, a major rainfall anomaly occurred in the study area from 2006 onwards causing severe drought stress (Fig. 8). Figure 6 illustrates a phenological change detected in 2006 with a seasonal segment (2006-2010) that has a smaller amplitude and a later start of the growing season compared to the other seasonal segments (i.e. 2000-2002 and 2002-2006) resulting from the piecewise robust linear regression. The trend component of Figures 6 and 7 also shows an abrupt change occurring in 2007 and a gradual decline (negative slope) from then onwards which confirms that the drought stress has a negative long term impact on the seasonal growth cycle. The occurrence of abrupt and gradual changes in the trend component in the study are further discussed in detail by Verbesselt et al. (2010).

\section{Discussion}

The detection of phenological change within seasonal time series containing noise, phenological, abrupt and gradual changes is discussed:

(1) BFAST can be used to detect significant long term phenological changes by exploiting the full time series while accounting for abrupt and gradual changes. Understanding of what constitutes significant change in land surface phenology (LSP) amidst background variation is a critical component of global change research (de Beurs and Henebry, 2005a). Exploiting the full time series enables the description of the continual process of LSP development, not just dates of specific events. Unlike in traditional ground-based phenology research in which dates may be recorded (e.g. flowering), LSP is the integral of multiple coincident growth cycles, non-climatic factors, and data quality (de Beurs and Henebry, 2004; White and Nemani, 2006). Furthermore, the high interannual 
variability of phenological metrics demonstrates the necessity of distinguishing annual seasonal variability from long term phenological change (Bradley and Mustard, 2008). In this study a long term phenological change is defined relative to the total length of the studied NDVI time series (i.e. 10 years) as a significant phenological change occurring over a period longer than two years. Long term phenological change within satellite image time series is a relative concept when compared to global change analysis dealing with in-situ phenology or climate data time series of 100 years and longer (Schwartz, 1999). Methods able to exploit full time series and detect long term changes will become more important in the context of ever increasing length of satellite image time series.

(2) Results illustrate that the capacity of BFAST to detect changes within time series is influenced by the signal-to-noise ratio of the time series. A wide range of NDVI specific noise levels representative for MODIS time series were simulated and used to assess BFAST's robustness against noise (Verbesselt et al., 2010). Results showed that BFAST has a low commission error for different noise levels when no phenological changes were simulated (no false positives). BFAST deals with noise in time series in two ways. First, robust linear regression is implemented to reduce the influence of outliers (e.g. clouds) (Venables and Ripley, 2002) when iteratively estimating the seasonal and trend model. Secondly, three harmonic terms are used to estimate the seasonal component of a time series and remove higher frequency variations such as noise and atmospheric scatter (Geerken, 2009).

Furthermore, it was shown that the detection of phenological change was influenced by the signal-to-noise ratio of the time series (i.e. seasonal amplitude versus noise). The lower the noise level and the larger the seasonal amplitude or phenological change within the time series, the easier it is to detect a phenological change within a time series. This confirms the importance of other available techniques to improve the signal-to-noise ratio of a time series. Elimination of noise within satellite image time series requires attention to issues of satellite calibration, orbital correction, detection and removal of atmospheric contamination, and image registration. Compositing of time series aims at lowering atmospheric and cloud influence (Holben, 1986), with different compositing periods ranging usually from 8 to 16 days. Compositing of time series and advanced cloud masking techniques do not fully eliminate effects of clouds 
and atmospheric contamination. Application of methods that estimate the upper envelope of the NDVI time series further reduce the influence of cloud contaminated values and improve the signal-to-noise ratio of a NDVI time series (Julien and Sobrino, 2010; Roerink et al., 2000; Viovy et al., 1992). In summary, BFAST deals with inherent noise in time series but the application of other available techniques which improve data quality remains important.

(3) It is shown that the seasonal amplitude of time series impacts the signal noise ratio and determines the capacity to detect phenological changes. Phenological changes can not be detected in seasonal time series having a signal-to-noise ratio smaller than one (e.g. having a seasonal amplitude $\leq 0.1$ and a noise range $\geq 0.1$ NDVI). Application of BFAST on real MODIS satellite image time series showed that more phenological changes were detected within grasslands than in $P$. radiata plantations. The seasonal amplitude of grasslands (i.e. $>0.3 \mathrm{NDVI}$ ) is significantly larger than for evergreen plantations (i.e. $<0.1$ NDVI). The simulation analysis supports these findings by illustrating that the detection of phenological change within time series is influenced by the signal-to-noise ratio. Moreover, simulation results also illustrated that phenological changes can still be detected within NDVI time series of the majority of the global land cover types, e.g. grasslands, woodlands, deciduous or open forests, having a larger signal-to-noise ratio $(>1)$. These findings corroborate results of Julien and Sobrino (2009) and de Beurs et al. (2009) by excluding time series exhibiting low seasonal amplitude from the phenological trend analysis. Julien and Sobrino (2009) did not analyze phenology trends in NDVI time series of biomes with a amplitude smaller than 0.1 that were extracted from the global GIMMS NDVI data set (1981-2003). These biomes correspond to arid or frozen area, as well as evergreen dense vegetation (Julien and Sobrino, 2009). Also, de Beurs et al. (2009) excluded MODIS NDVI time series from the analysis with a coefficient of variation $<5 \%$ to ensure sufficient seasonality to produce reliable trend estimates of extracted phenological metrics. Furthermore, the detection of phenological change in evergreen forests is difficult with remotely sensed NDVI time series since the NDVI tends to saturate for high biomass regions such as evergreen forests (Huete et al., 2002). Other more sensitive remotely sensed indices for high biomass regions such as the Enhanced Vegetation index (Huete et al., 2002) 
or SWIR-based indices (Hunt and Rock, 1989; de Beurs and Townsend, 2008) may produce better results.

\section{Further work and applications}

(1) The BFAST algorithm can potentially be used for studies of vegetation dynamics and phenology in two ways (Fig. 9). First, as illustrated in this study BFAST can be used to detect long term phenological changes within time series by analyzing the seasonal component of the time series for changes in phenology (Fig. 9, $S_{t}$ ). Phenological changes are detected independent of the change type since a harmonic model is used that accommodates for a large range of land cover types (Jakubauskas et al., 2001). The detected phenological changes can be characterized by the fitted parameters of the harmonic model (i.e. $a_{j}$ and $\delta_{j}$ ). Second, underlying trend can be removed from time series to improve the data quality (Fig. $9, Y_{t}-T_{t}$ ). For example, satellite sensor errors have a longer term impact on the signal (e.g. sensor drift and calibration problems) and will affect the underlying trend in long time series (Bradley and Mustard, 2008). As such, by removing the underlying trends from the original time series to correct for satellite sensor errors having an impact on the signal. Available methods to extract phenological metrics can be applied on these trend corrected time series.

(2) The utility of the time series simulation approach proposed in this study provides the ability to test phenological change detection methods in a controlled environment. While validation is a key issue in remotely sensed phenology studies over large areas (Reed et al., 2003; Schwartz et al., 2002; White et al., 2009), field data defining full seasonal growth cycles over multiple years is lacking. Traditional ground-based phenology research has been focussing on recording specific dates (e.g. flowering or budburst) (Schwartz, 1999) whereas satellite sensors record daily information about LSP requiring a similar type of temporally continuous field data to be collected. This explains why relationships between remotely sensed LSP and plant phenology are generally unknown (White and Nemani, 2006). The simulation of time series approach enables the assessment of methods to study phenological changes in a controlled environment by varying the signal-to-noise ratio and combining it with simulated changes within time series. 
(3) The parametric seasonal and trend models used within BFAST provide a natural framework for real time monitoring and forecasting. White and Nemani (2006) proposed a conceptual approach to real time monitoring and short term forecasting of LSP. Although White and Nemani (2006) state that phenology information should not be provided for individual pixels (individual time series) there are some corresponding principles. First, BFAST also avoids defining phenological metrics and detects phenological change based on a significant difference between phenological models by employing a piecewise robust linear regression. Second, the estimated models in BFAST can not only be assessed using historical data to detect changes; but given the detected changes, short term forecasts from the last stable model can be derived (Pesaran and Timmermann, 2002). The deviations between these forecasts and the incoming observations can be utilized for monitoring the stability of the model in real time (Zeileis, 2005). Further work is required to evaluate and demonstrate BFAST for real monitoring and forecasting.

\section{Conclusion}

A challenge to phenology studies is understanding what constitutes long term phenological change amidst background variation (e.g. fires, land degradation, and noise). Here, we demonstrated the ability of a method to detect long term phenological change by analyzing time series containing noise, abrupt, and gradual changes. Exploiting full time series enables the description of the continual process of land surface phenology, not just dates of specific events. The method, BFAST (Breaks For Additive Seasonal and Trend), iteratively estimates the dates and number of changes occurring within seasonal and trend components (Verbesselt et al., 2010). The method has been improved by implementing a harmonic seasonal model which requires fewer observations, is more robust against noise, and of which the parameters can be more easily used to characterize phenological change.

We tested BFAST (1) by simulating 16-day NDVI time series with varying seasonal amplitude and noise, containing an abrupt trend change and long term phenological changes, and (2) by applying on MODIS NDVI time series covering a forested area in south eastern Australia. Results showed that the number and timing of detected phenological changes within time series is influenced by the signal-to-noise ratio of the analyzed time series. BFAST deals with inherent noise in time series using robust linear regression techniques 
and using only the first three harmonic terms for the seasonal model estimation. However, it remains important to improve the data quality of time series by using existing techniques to reduce the noise level and increase the signal-to-noise ratio. It is shown that the seasonal amplitude of NDVI time series impacts the signal-to-noise ratio and determines the ability to detect phenological changes. Phenological changes caused by a change in SOS can not be detected in seasonal time series having a signal-to-noise ratio smaller than one (i.e. having a seasonal amplitude $\leq 0.1$ NDVI and a noise range $\geq 0.1$ NDVI). Other more sensitive remotely sensed indices for high biomass regions (i.e. evergreen forests) may improve the detection of phenological changes by increasing the measured seasonal amplitude. However, phenological changes can still be detected within NDVI time series of the majority of the global land cover types, e.g. grasslands, woodlands, deciduous or open forests, having a signal-to-noise ratio $>1$.

The proposed method can be used in two ways for phenology studies. First, as demonstrated here it can be used to detect long term phenological changes within time series. Second, it can be used to remove underlying abrupt and gradual trend changes and improve the quality of time series data before for example extraction of phenological metrics. BFAST can be applied to any time series data and it is not limited to NDVI. The method described in this study are available in the BFAST package for $\mathrm{R}$ ( $\mathrm{R}$ Development Core Team, 2009) from CRAN (http://cran.r-project.org/package=bfast).

\section{Acknowledgements}

This work was undertaken within the program of the Cooperative Research Center for Forestry: Monitoring and Measuring (http://www.crcforestry.com.au). Thanks to Dr. Glenn Newnham and Dr. Michael Dunlop whose comments greatly improved this paper. We greatly appreciate the constructive feedback we have received from the three reviewers.

\section{References}

Anyamba, A., Eastman, J. R., 1996. Interannual variability of NDVI over Africa and its relation to El Nino Southern Oscillation. International Journal of Remote Sensing 17 (13), 2533-2548. 
Azzali, S., Menenti, M., 2000. Mapping vegetation-soil-climate complexes in southern Africa using temporal Fourier analysis of NOAA-AVHRR NDVI data. International Journal of Remote Sensing 21 (5), 973-996.

Bai, J., Perron, P., 2003. Computation and analysis of multiple structural change models. Journal of Applied Econometrics 18 (1), 1-22.

Bontemps, S., Bogaert, P., Titeux, N., Defourny, P., 2008. An object-based change detection method accounting for temporal dependences in time series with medium to coarse spatial resolution. Remote Sensing of Environment 112 (6), 3181-3191.

Bradley, B. A., Jacob, R. W., Hermance, J. F., Mustard, J. F., 2007. A curve fitting procedure to derive inter-annual phenologies from time series of noisy satellite NDVI data. Remote Sensing of Environment 106 (2), 137-145.

Bradley, B. A., Mustard, J. F., 2008. Comparison of phenology trends by land cover class: a case study in the Great Basin, USA. Global Change Biology 14 (2), 334-346.

Cleland, E. E., Chuine, I., Menzel, A., Mooney, H. A., Schwartz, M. D., 2007. Shifting plant phenology in response to global change. Trends in Ecology \& Evolution 22 (7), $357-365$.

Coppin, P., Jonckheere, I., Nackaerts, K., Muys, B., Lambin, E., 2004. Digital change detection methods in ecosystem monitoring: a review. International Journal of Remote Sensing 25 (9), 1565-1596.

Crist, E. P., Cicone, R. C., 1984. A physically-based transformation of thematic mapper data - The TM tasseled cap. IEEE Transactions on Geoscience and Remote Sensing $22(3), 256-263$.

de Beurs, K., Wright, C., Henebry, G., 2009. Dual scale trend analysis for evaluating climatic and anthropogenic effects on the vegetated land surface in Russia and Kazakhstan. Environmental Research Letters 4 (4).

de Beurs, K. M., Henebry, G. M., Oct. 2004. Trend analysis of the pathfinder avhrr land (pal) NDVI data for the deserts of central Asia. Geoscience and Remote Sensing Letters, IEEE 1 (4), 282-286. 
de Beurs, K. M., Henebry, G. M., 2005a. Land surface phenology and temperature variation in the International Geosphere-Biosphere Program high-latitude transects. Global Change Biology 11 (5), 779-790.

de Beurs, K. M., Henebry, G. M., 2005b. A statistical framework for the analysis of long image time series. International Journal of Remote Sensing 26 (8), 1551-1573.

de Beurs, K. M., Townsend, P. A., 2008. Estimating the effect of gypsy moth defoliation using MODIS. Remote Sensing of Environment 112 (10), 3983-3990.

Eastman, J. R., Sangermano, F., Ghimire, B., Zhu, H., Chen, H., Neeti, N., Cai, Y., Machado, E. A., Crema, S. C., 2009. Seasonal trend analysis of image time series. International Journal of Remote Sensing 30 (10), 2721-2726.

Fensholt, R., Rasmussen, K., Nielsen, T. T., Mbow, C., 2009. Evaluation of earth observation based long term vegetation trends - intercomparing NDVI time series trend analysis consistency of Sahel from AVHRR GIMMS, Terra MODIS and SPOT VGT data. Remote Sensing of Environment 113 (9), 1886 - 1898.

Geerken, R. A., 2009. An algorithm to classify and monitor seasonal variations in vegetation phenologies and their inter-annual change. ISPRS Journal of Photogrammetry and Remote Sensing 64 (4), 422-431.

Holben, B. N., 1986. Characteristics of maximum-value composite images from temporal AVHRR data. International Journal of Remote Sensing 7 (11), 1417-1434.

Huete, A., Didan, K., Miura, T., Rodriguez, E. P., Gao, X., Ferreira, L. G., 2002. Overview of the radiometric and biophysical performance of the MODIS vegetation indices. Remote Sensing of Environment 83 (1-2), 195-213.

Hunt, E. R., Rock, B. N., 1989. Detection of change in leaf water-content using near-infrared and middle-infrared reflectances. Remote Sensing of Environment 30 (1), 43-54.

Jakubauskas, M. E., Legates, D. R., Kastens, J. H., 2001. Harmonic analysis of time-series AVHRR NDVI data. Photogrammetric Engineering and Remote Sensing 67 (4), 461-470.

Jeffrey, S. J., Carter, J. O., Moodie, K. B., Beswick, A. R., 2001. Using spatial interpolation to construct a comprehensive archive of australian climate data. Environmental Modelling \& Software 16 (4), 309-330. 
Schwartz, M. D., 1999. Advancing to full bloom: planning phenological research for the 21st century. International Journal of Biometeorology 42 (3), 113-118.

database. International Journal of Remote Sensing 30 (13), 3495-3513.

Julien, Y., Sobrino, J. A., 2010. Comparison of cloud-reconstruction methods for time series of composite ndvi data. Remote Sensing of Environment 114 (3), 618-625.

Lambin, E. F., Strahler, A. H., 1994. Change-Vector Analysis in multitemporal space - a tool to detect and categorize land-cover change processes using high temporal-resolution satellite data. Remote Sensing of Environment 48 (2), 231-244.

Linderholm, H. W., 2006. Growing season changes in the last century. Agricultural and Forest Meteorology 137 (1-2), 1-14.

Makridakis, S., Wheelwright, S. C., Hyndman, R. J., 1998. Forecasting: methods and applications, 3rd Edition. John Wiley \& Sons, New York.

Parmesan, C., Yohe, G., 2003. A globally coherent fingerprint of climate change impacts across natural systems. Nature 421 (6918), 37-42.

Pesaran, M. H., Timmermann, A., 2002. Market timing and return prediction under model instability. Journal of Empirical Finance 9, 495-510.

Potter, C., Tan, P. N., Steinbach, M., Klooster, S., Kumar, V., Myneni, R., Genovese, V., 2003. Major disturbance events in terrestrial ecosystems detected using global satellite data sets. Global Change Biology 9 (7), 1005-1021.

R Development Core Team, 2009. R: A Language and Environment for Statistical Computing. R Foundation for Statistical Computing, Vienna, Austria.

URL http://www.R-project.org

Reed, B. C., White, M., Brown, J. F., 2003. Remote sensing phenology. Phenology: an Integrative Environmental Science 39, 365-381.

Roerink, G., Menenti, M., Verhoef, W., 2000. Reconstructing cloudfree NDVI composites using Fourier analysis of time series. International Journal of Remote Sensing 21 (9), 1911-1917. 
Schwartz, M. D., Reed, B. C., White, M. A., 2002. Assessing satellite-derived start-ofseason measures in the conterminous USA. International Journal of Climatology 22 (14), 1793-1805.

Townshend, J. R. G., Justice, C. O., 1988. Selecting the spatial-resolution of satellite sensors required for global monitoring of land transformations. International Journal of Remote Sensing 9 (2), 187-236.

Venables, W. N., Ripley, B. D., 2002. Modern applied statistics with S, 4th Edition. Springer-Verlag.

Verbesselt, J., Hyndman, R., Newnham, G., Culvenor, D., 2010. Detecting trend and seasonal changes in satellite image time series. Remote Sensing of Environment 114 (1), $106-115$.

Verbesselt, J., Jönsson, P., Lhermitte, S., van Aardt, J., Coppin, P., 2006. Evaluating satellite and climate data derived indices as fire risk indicators in savanna ecosystems. IEEE Transactions on Geoscience and Remote Sensing 44 (6), 1622-1632.

Viovy, N., Arino, O., Belward, A. S., 1992. The Best Index Slope Extraction (BISE) - a method for reducing noise in NDVI time-series. International Journal of Remote Sensing $13(8), 1585-1590$.

Wagenseil, H., Samimi, C., 2006. Assessing spatio-temporal variations in plant phenology using Fourier analysis on ndvi time series: results from a dry savannah environment in namibia. International Journal of Remote Sensing 27 (16), 3455-3471.

White, M. A., de Beurs, K. M., Didan, K., Inouye, D. W., Richardson, A. D., Jensen, O. P., O'Keefe, J., Zhang, G., Nemani, R. R., van Leeuwen, W. J. D., Brown, J. F., de Wit, A., Schaepman, M., Lin, X., Dettinger, M., Bailey, A. S., Kimball, J., Schwartz, M. D., Baldocchi, D. D., Lee, J. T., Lauenroth, W. K., 2009. Intercomparison, interpretation, and assessment of spring phenology in North America estimated from remote sensing for 1982-2006. Global Change Biology 15, 2335-2359.

White, M. A., Nemani, A. R., 2003. Canopy duration has little influence on annual carbon 605 storage in the deciduous broad leaf forest. Global Change Biology 9 (7), 967-972. 
White, M. A., Nemani, R. R., 2006. Real-time monitoring and short-term forecasting of land surface phenology. Remote Sensing of Environment 104 (1), 43-49.

White, M. A., Thornton, P. E., Running, S. W., 1997. A continental phenology model for monitoring vegetation responses to interannual climatic variability. Global Biogeochemical Cycles $11(2), 217-234$.

Zeileis, A., 2005. A unified approach to structural change tests based on ML scores, $F$ statistics, and OLS residuals. Econometric Reviews 24 (4), 445-466.

Zeileis, A., Kleiber, C., 2005. Validating multiple structural change models - A case study. Journal of Applied Econometrics 20 (5), 685-690.

Zeileis, A., Kleiber, C., Krämer, W., Hornik, K., 2003. Testing and dating of structural changes in practice. Computational Statistics and Data Analysis 44, 109-123.

Zeileis, A., Leisch, F., Hornik, K., Kleiber, C., 2002. strucchange: An R package for testing for structural change in linear regression models. Journal of Statistical Software 7 (2), $1-38$. B. C., Huete, A., 2003. Monitoring vegetation phenology using MODIS. Remote Sensing of Environment 84 (3), 471-475. 


\section{Figures}

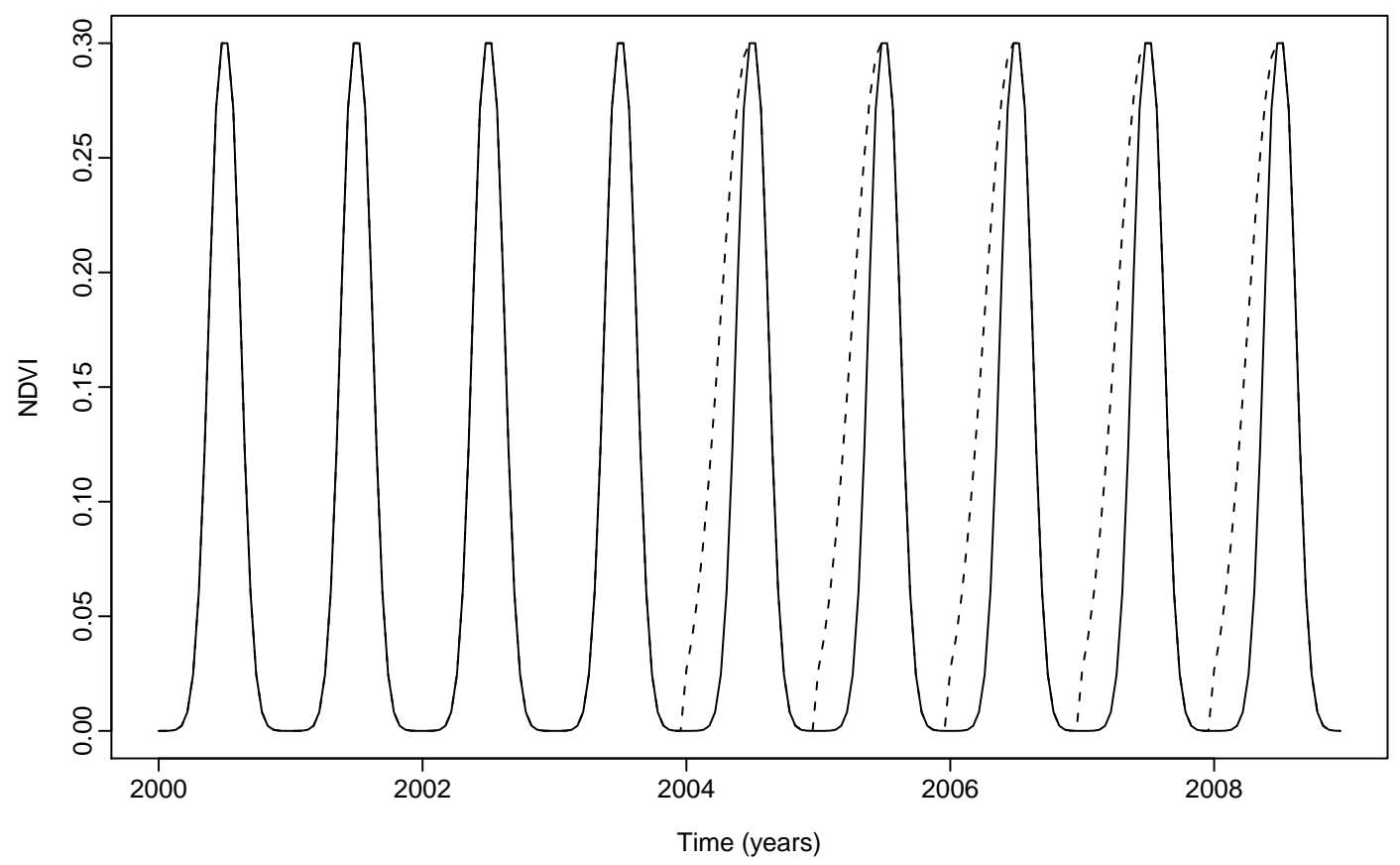

Figure 1: Simulated seasonal change introduced by changing the $c_{1}$ from 5 (-) to 25 (dashed) from 2004 onwards while having $c_{2}=5, b=12$, and a seasonal amplitude of 0.3 NDVI (Eq. 5). 


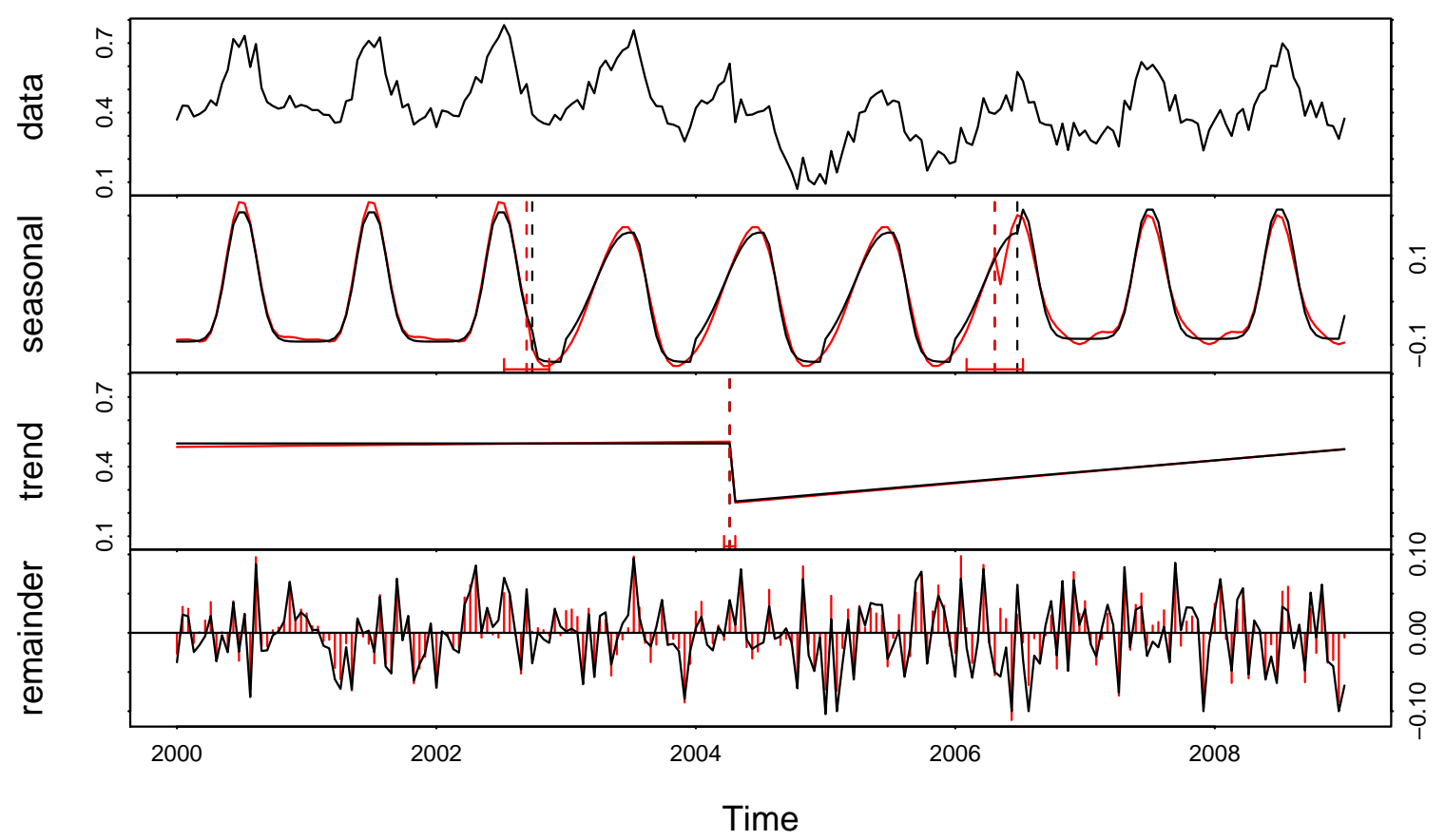

Figure 2: Simulated 16-day MODIS NDVI time series with a seasonal amplitude $=0.3$, $\sigma=0.04$, containing one simulated abrupt change in the trend (magnitude $=$ $-0.25)$ and 2 simulated phenological changes in the seasonal component $(+$ 30 and $\left.-30 \Delta c_{1}\right)$ (Table 1). The estimated seasonal, trend and remainder series are shown in red. The time of estimated (red) and simulated (black) trend and seasonal changes is indicated by the vertical dotted line. One trend breakpoint and two seasonal breakpoints are detected and confidence intervals of the estimated time of change are shown (red). The simulated data series is the sum of the simulated seasonal, trend and noise series (black), and is used as an input in BFAST. 


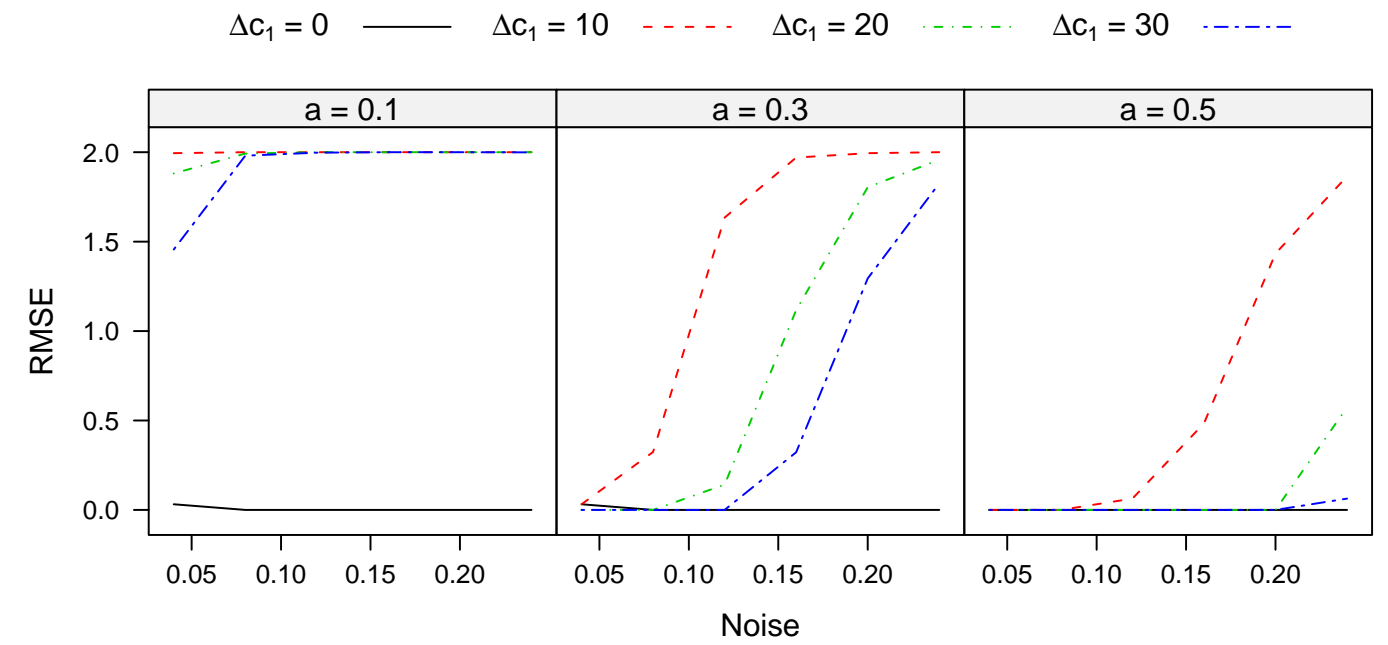

Figure 3: RMSEs for estimating the number of phenological changes caused by a change in $\Delta c_{1}$ where $a$ is the amplitude of the simulated seasonal component (e.g. as in Fig. 1). The values of parameters used for the simulation of the 16-day NDVI time series are shown in Table 1. The units of the $x$ and $y$-axes are $4 \sigma$ (i.e. $99 \%$ of the noise range) and the number of changes (RMSE). If $\Delta c_{1}>$ 0 , two phenological changes are simulated and when both changes are detected the $R M S E=0$ and when no changes are detected the $R M S E=2$. If $\Delta c_{1}=0$, no phenological changes are simulated and when no changes are detected the $R M S E=0$. 


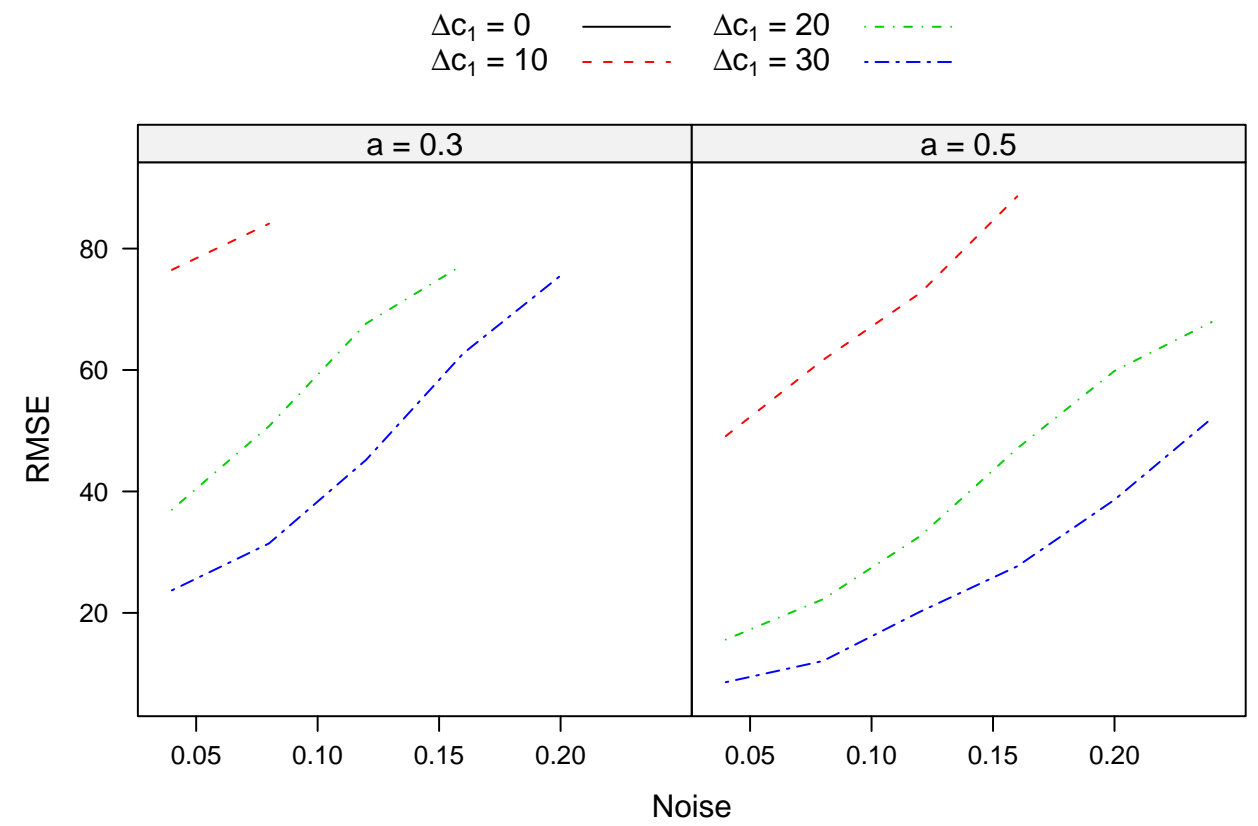

Figure 4: RMSEs for estimating the time of phenological change caused by a change in $\Delta c_{1}$ where $a$ is the overall amplitude of the seasonal component (e.g. as in Fig. 1). The units of the $x$-axis are $4 \sigma$ NDVI (i.e. $99 \%$ of the noise range), and $y$-axis is time (days). See Table 1 for the values of parameters used for the simulation of 16-day NDVI time series. No results are shown for $a=0.1$ when $\Delta c_{1}=0$ since almost no phenological changes were detected (Fig. 3). 


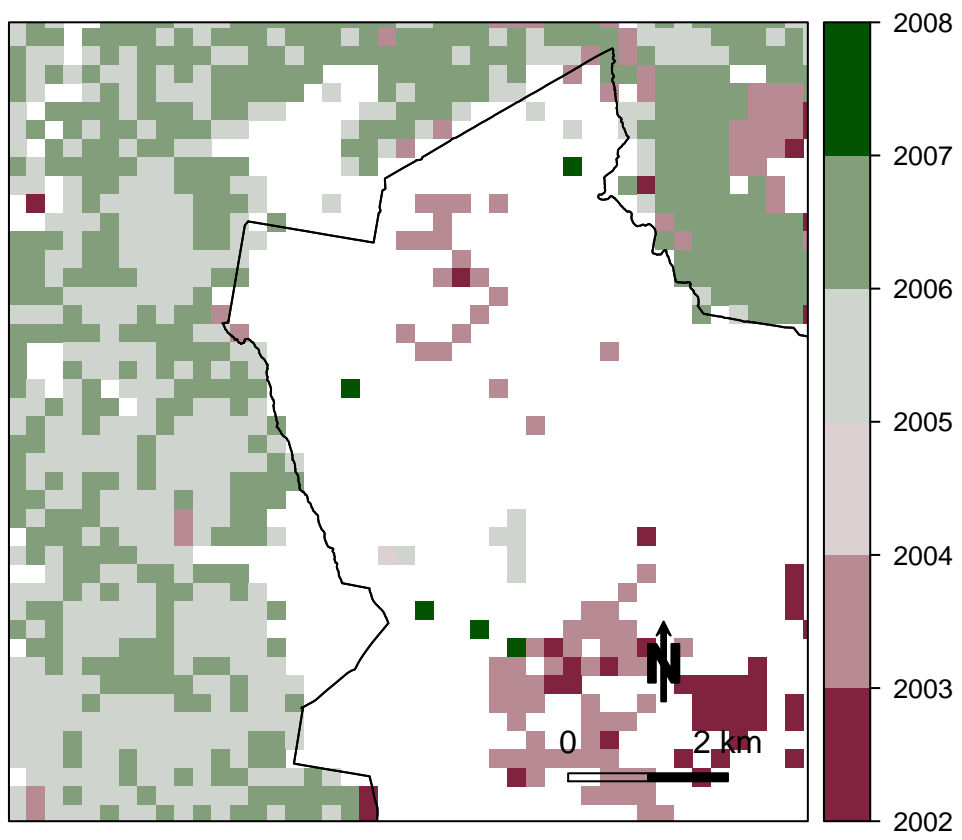

Figure 5: Timing of long term phenological changes detected in MODIS NDVI image time series (2000-2009) for a forested area in south eastern Australia. The minimum period between breaks is two years, which means that detected change is occurring over a period of two years or longer (see 2.2). The black line indicates the boundary of the Pinus radiata plantation, which corresponds to the area (white $=$ no change) where less changes are detected. The plantation is surrounded by grasslands. 


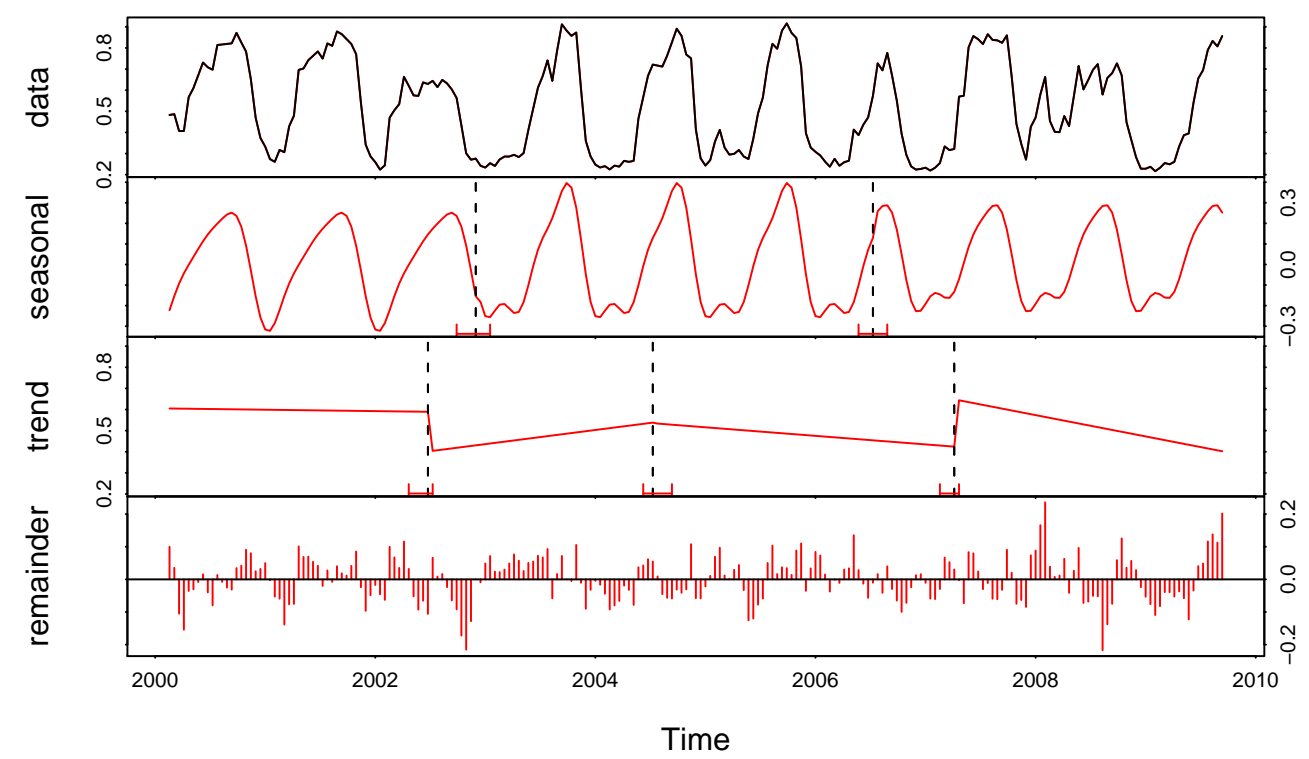

Figure 6: Detected changes in the seasonal and trend component (red) of 16-day NDVI time series (data) extracted from a single MODIS pixel of a grassland (Lat. $35.4^{\circ} \mathrm{S}$, Lon. $147.9^{\circ} \mathrm{E}$ ). The estimated average seasonal amplitude of the seasonal component is 0.7, with $\Delta a$ of -0.1 for the seasonal change detected in 2006. Three abrupt changes are detected in the trend component. The time of change (- - ), together with its confidence intervals (red) are also shown. 


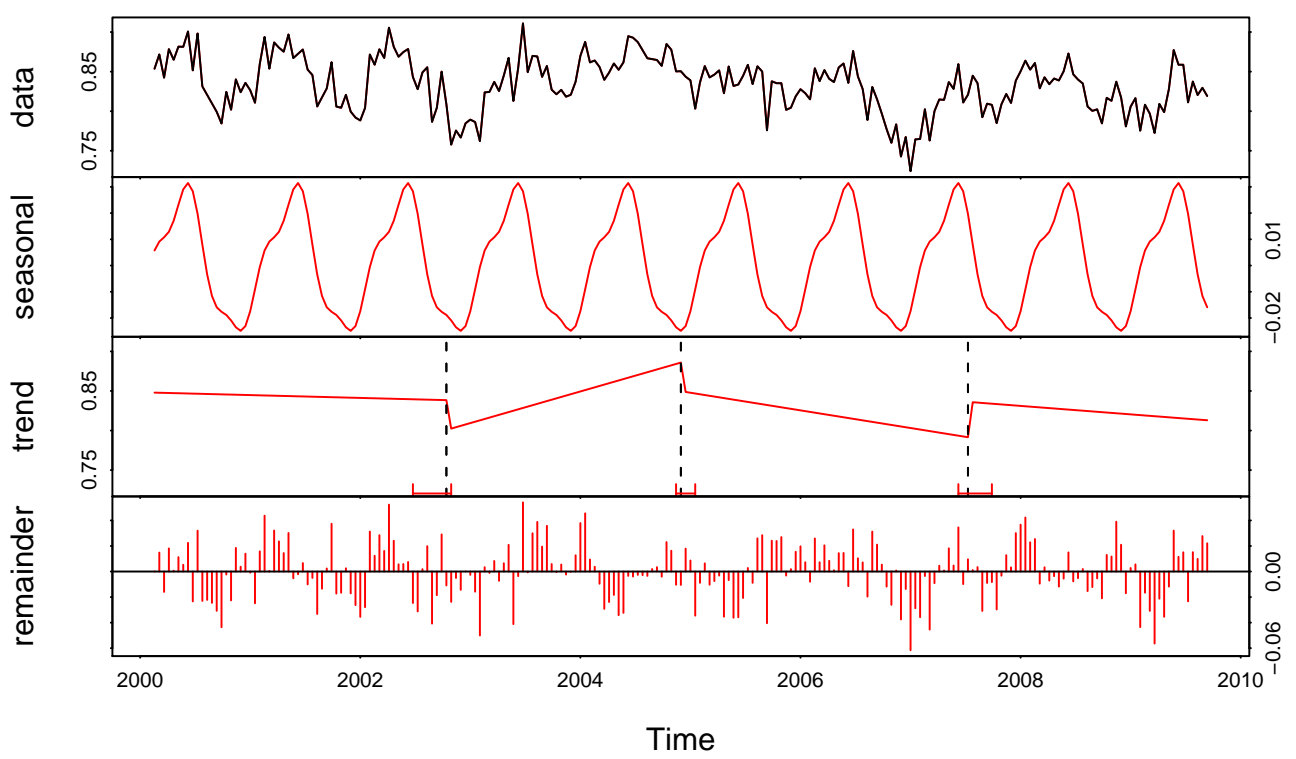

Figure 7: Detected changes in trend component (red) of 16-day NDVI time series (data) extracted from a single MODIS pixel of a Pinus radiata plantation (Lat. $35.5^{\circ} \mathrm{S}$, Lon. $148.0^{\circ}$ E) with plant year 1974. The estimated average seasonal amplitude of the seasonal component is 0.1 , with three abrupt changes detected in the trend component and no phenological changes detected in the seasonal component. The time of change (- - ), together with its confidence intervals (red) are also shown. 


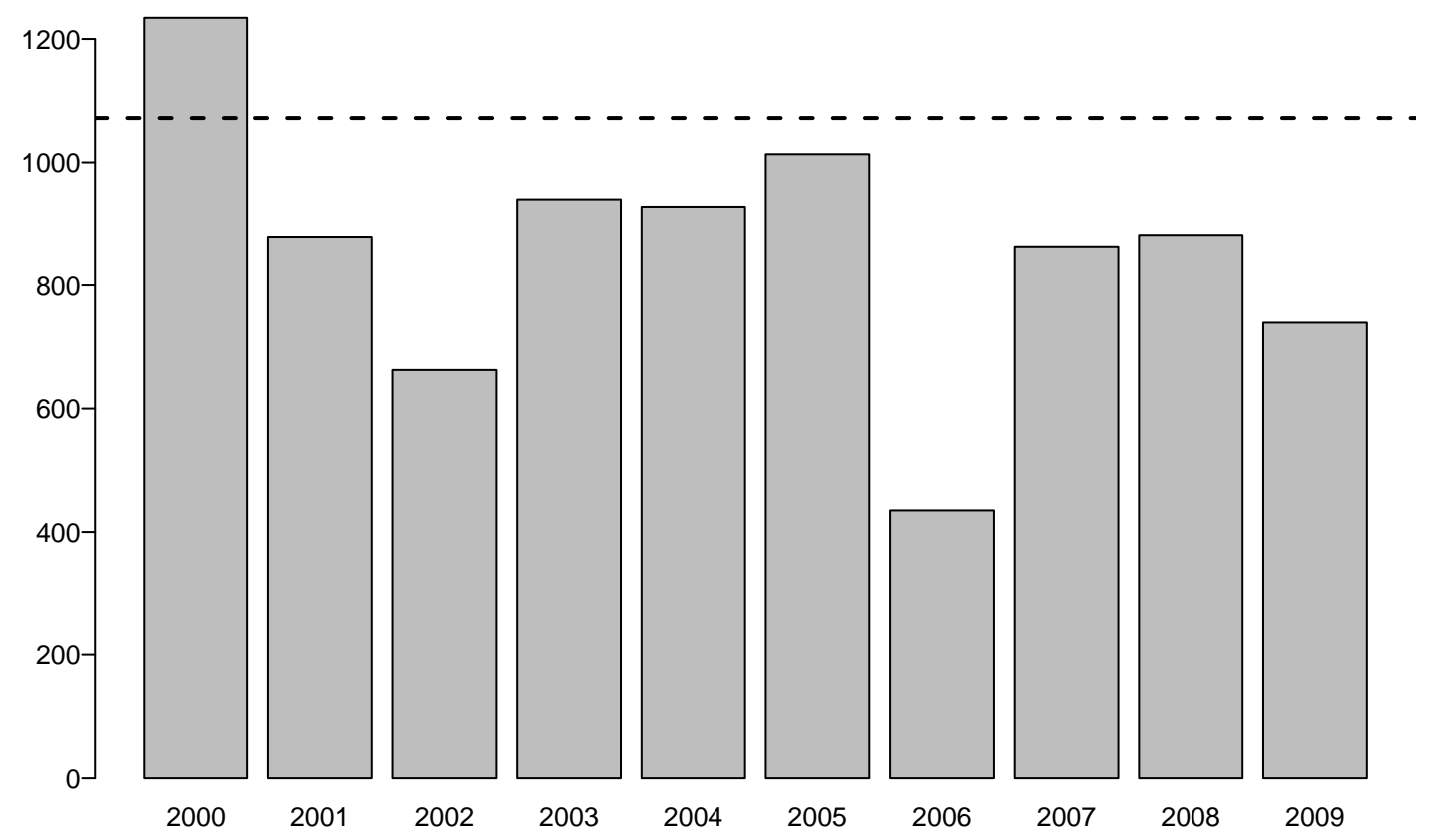

Figure 8: Annual rainfall (mm/year) for North Western part of Green Hills State Forest where the (-) line illustrates the mean annual rainfall, $1072 \mathrm{~mm} /$ year between 1940-2009 derived from interpolated rainfall surfaces with a spatial resolution of $500 \mathrm{~m}$ (Jeffrey et al., 2001). 


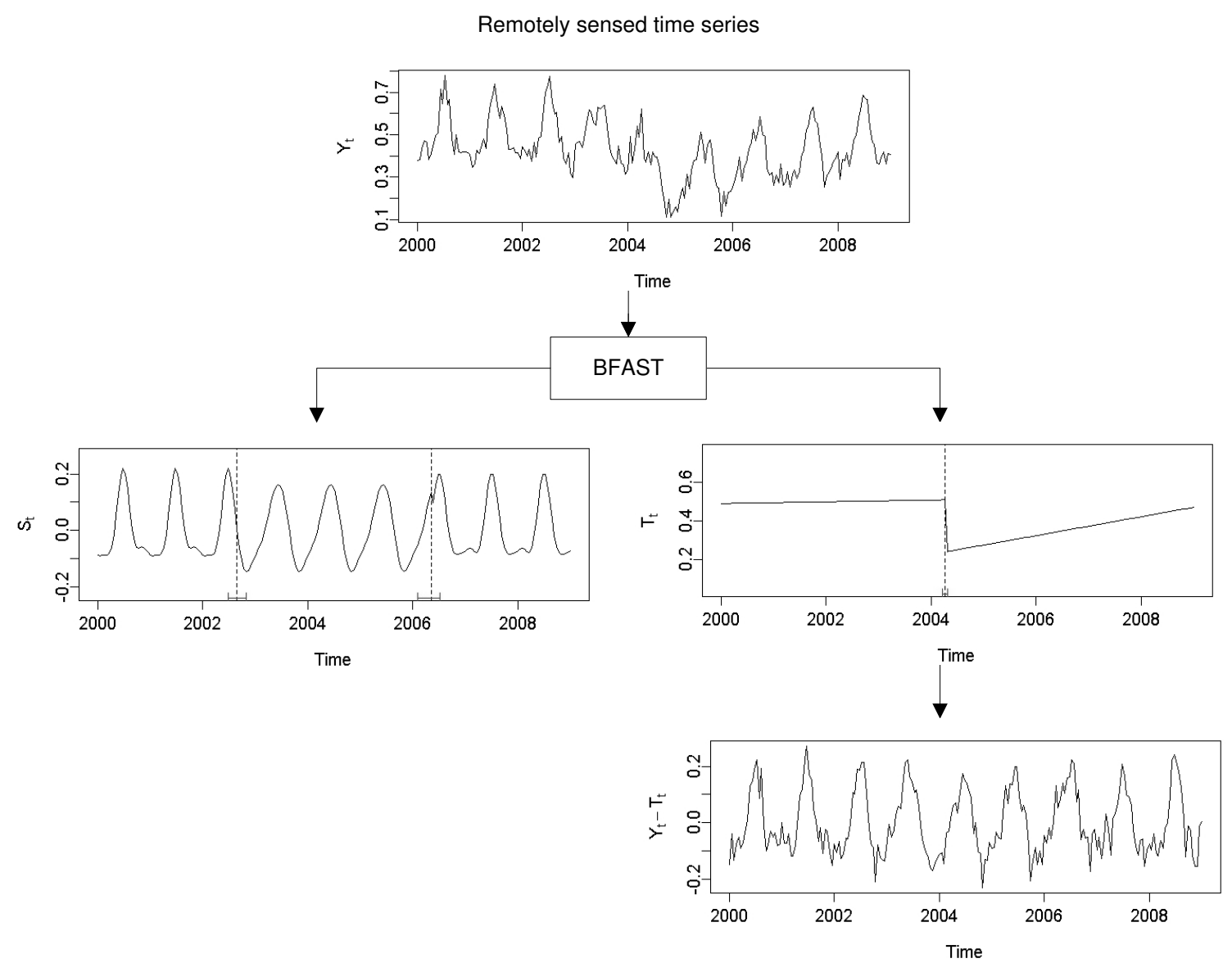

Figure 9: A flow chart illustrating how BFAST can be used for phenology studies. $Y_{t}$ is a simulated 16-day NDVI time series used as an input (Fig. 2). First, the method can be used to detect phenological change within time series (left). Two phenological changes are detected in the seasonal component $\left(S_{t}\right)$. Second, time series can be corrected for underlying trends by accounting for abrupt and gradual changes (right). One abrupt change and a gradual recovery is shown in the trend component $\left(T_{t}\right)$ and used to obtain the trend corrected time series, $Y_{t}-T_{t}$. 